\title{
Legacy Data in 3D: The Cape Andreas Survey (1969-1970) and Santo António de Tanná Expeditions (1978-1979)
}

\author{
Jeremy Green
}

\begin{abstract}
This chapter explores the significance of legacy data as a source of new information and the possibility of extracting new information from sources of information that were recovered before the advent of computers and the digital revolution. Since then, much of the emphasis has been directed towards gathering new information and there has been little emphasis on records that date back over 50 years. This chapter examines two examples: the first the Cape Andreas Expedition in Cyprus 1969-1970 and the other the Santo António de Tanná excavation 1977-1980. Both case studies are examined for the elements of photography that can be used to extract new information and how data, in the future, can be best be collected to suit these developments.
\end{abstract}

\section{Keywords}

Cape Andreas · Cyprus · Kenya $\cdot$ Legacy data . Portuguese frigate $\cdot$ Santo António de Tanná $\cdot$ Shipwreck survey

\subsection{Introduction}

This chapter underlines the significance of legacy data as an important source of new information. The legacy data described in this chapter was collected in the late 1960s and 1970s. This was a time before desktop computers and GPS, when underwater cameras were just becoming more available and the underwater archaeological world was in its infancy. It is interesting to remember that, in those days, locating underwater archaeological sites was exceedingly difficult. Position could only be determined close to shore

\section{J. Green $(\bowtie)$}

Department of Maritime Archaeology, WA Museum,

Fremantle, WA, Australia

e-mail: jeremy.green@museum.wa.gov.au where land transits were the most reliable method and to some extent still are today, although they suffer from a lack of permanency. Additionally, where a survey track was required, horizontal sextant angles was the cheapest, although by far the most difficult method to utilize. Once out of sight of land, there was nothing available to the archaeologist, other than various offshore commercial electronic positioning systems, such as HiFix and MiniRanger; well beyond the budget of most archaeological projects. Surveying underwater archaeological sites was also difficult. Essentially, survey work relied on trilateration or simple offset surveys using tape measures and there was almost no possibility to work in $3 \mathrm{D}$ as the only available calculating systems available, at least in the early 1970s, was the slide-rule and log tables. Photography in the field was also difficult. Film cameras could only take up to 36 pictures before they required reloading; processing and printing in the field was difficult, as a dark room with processing facilities and an enlarger were required. This was the environment where the legacy data described in this chapter was collected.

This chapter deals with two projects that the author was involved in and which have been selected to illustrate the processing of legacy data. The first project was at Cape Andreas, Cyprus, which was the first archaeological project the author directed. The objectives of this project were based on the author's previous experience working with George Bass at Yassiada in Turkey and later with Michael Katzev on the Kyrenia excavation. After Cape Andreas, the author came to the Western Australian Museum and conducted the excavation of the Dutch East India shipwreck Batavia. The processing of the legacy data from that shipwreck is the subject of a $\mathrm{PhD}$ thesis and will not be discussed here (McAllister 2018). In 1978-1979 the photographic survey of the Portuguese frigate Santo António de Tanná, wrecked in Mombasa harbour in 1697 was undertaken. The two projects will be discussed in more detail below; however, some background to the two projects is required. As the primary objective of Cape Andreas work was to locate and survey 
underwater archaeological sites, it presented an opportunity to investigate and explore new techniques and technology. At that time the underwater swim-line survey technique had only recently been developed, and the Admiralty Manual of Hydrographic Surveying (Hydrographer of the Navy 1965) provided information on maritime survey techniques. An experimental underwater theodolite was constructed to try and improve underwater site surveying. Photographic techniques were investigated using the Nikonos camera with refraction-corrected lens, which had only just become available. Bass et al. (1967) had developed an underwater photomosaic system at Cape Gelidonya and Williams (1969) had published Simple Photogrammetery, which introduced a range of photogrammetric techniques that could be applied underwater. With this range of techniques, the Cape Andreas project was undertaken.

The Mombasa survey, on the other hand, was a much more specific project. The hull of the ship was uncovered during the two seasons of excavation, and the objective was to record this in order to produce a site plan. By the late 1970s, technology had progressed. Programmable calculators were available; the Nikonos camera now had a $20 \mathrm{~mm}$ underwater-corrected lens and the author had worked in Australia to develop a stereo-bar photo tower to record sites. These techniques were used to record the complex hull structure of the Santo António de Tanná.

As it turned out. both projects subsequently provided an opportunity to reassess the data. With the advent of computers, Geographical Information Systems (GIS), satellite imagery and programs that allowed the data to be reprocessed, the subject of this chapter turns to examine the data collection methodology, the reprocessing of the data and the outcomes. While much has been published on the recent use of underwater photogrammetry with digital cameras, the author has found no references to published work on retrospective or legacy photogrammetric analysis for maritime archaeology. This is surprising as it is an area with huge potential. This is now beginning to be recognized the field of archaeology (Wallace 2017) and palaeontology (Falkingham et al. 2014; Lallensack et al. 2015).

\subsection{Cape Andreas Expeditions}

In 1969 and 1970, the Oxford University Research Laboratory for Archaeology conducted two underwater archaeological survey expeditions to Cape Andreas, Cyprus (Fig. 3.1), to record underwater archaeological material including shipwreck sites and anchors. The sites were found using a swim-line search technique, and they were then surveyed and photographed. The results were the subject of two publications (Green 1969, 1971b). This material has lain dormant and only recently, with the advent of a number of computer-related techniques, has now been reassessed. The positions of the sites, although accurately recorded on topographical maps at the time, did not have geographical coordinates, making it almost impossible to relocate them in the future. Using the original data, it has been possible, with the use of satellite imagery and the Esri ArcGIS program, to precisely locate all the sites and attribute approximate geographical coordinates (latitude and longitude) to them, ensuring the possibility of relocation in the future (Fig. 3.2).

The possibility of revisiting the data for these sites is due to the fact that both of these early maritime archaeological expeditions featured experiments in underwater photogrammetric techniques, which at that time were in their infancy. The expeditions used the relatively new underwater Nikonos $35 \mathrm{~mm}$ camera with a $27 \mathrm{~mm}$ water corrected lens to create photomosaics and to record sites and objects. The photographic data has now been reprocessed using Agisoft PhotoScan/Metashape and has resulted in some remarkable $3 \mathrm{D}$ plans of the sites.

The author had been involved in the Cyprus Archaeological Underwater Survey Expedition (CAUSE) that had visited the Cape in 1967, with a team from The University Museum, Pennsylvania and the Oxford University Research Laboratory for Archaeology (Green et al. 1967), and as the area seemed to be promising for a future survey it was selected for the project. The main objective of the Cape Andreas expeditions was to survey the seabed around the Cape and Khlides Islands for wreck sites and other archaeological material. As the water clarity around the Cape often produced visibility of around $70 \mathrm{~m}$, the survey planned to use a swim-line technique with divers swimming at a depth of around $20 \mathrm{~m}$ visually searching the seabed up to a depth of $50 \mathrm{~m}$. The divers were spaced at regular intervals on a line so that adjacent divers could see the same area, thus ensuring the seabed was systematically searched.

As there were no detailed hydrographic charts of the Cape Andreas area, the first priority of the 1969 expedition was to produce a detailed chart of the Cape delineating the $50 \mathrm{~m}$ contour. To do this an echo sounder was used to measure the depth and the position of the survey vessel was recorded using horizontal sextant angles to stations on the islands and Cape. As there were no survey points on the chain of islands extending from the Cape, the most detailed plan, at that time, was an aerial photograph. Therefore, the survey work had to start from scratch. Using a theodolite, a series of prominent survey stations on the islands were established that could be seen from the sea. Once established, the survey vessel made a series of runs perpendicular to the shore recording the track of the vessel with the horizontal sextants. Each sextant 'fix' was marked on the sonar paper trace and subsequently the data transferred to the plan. This enabled an accurate plan of the depth con- 


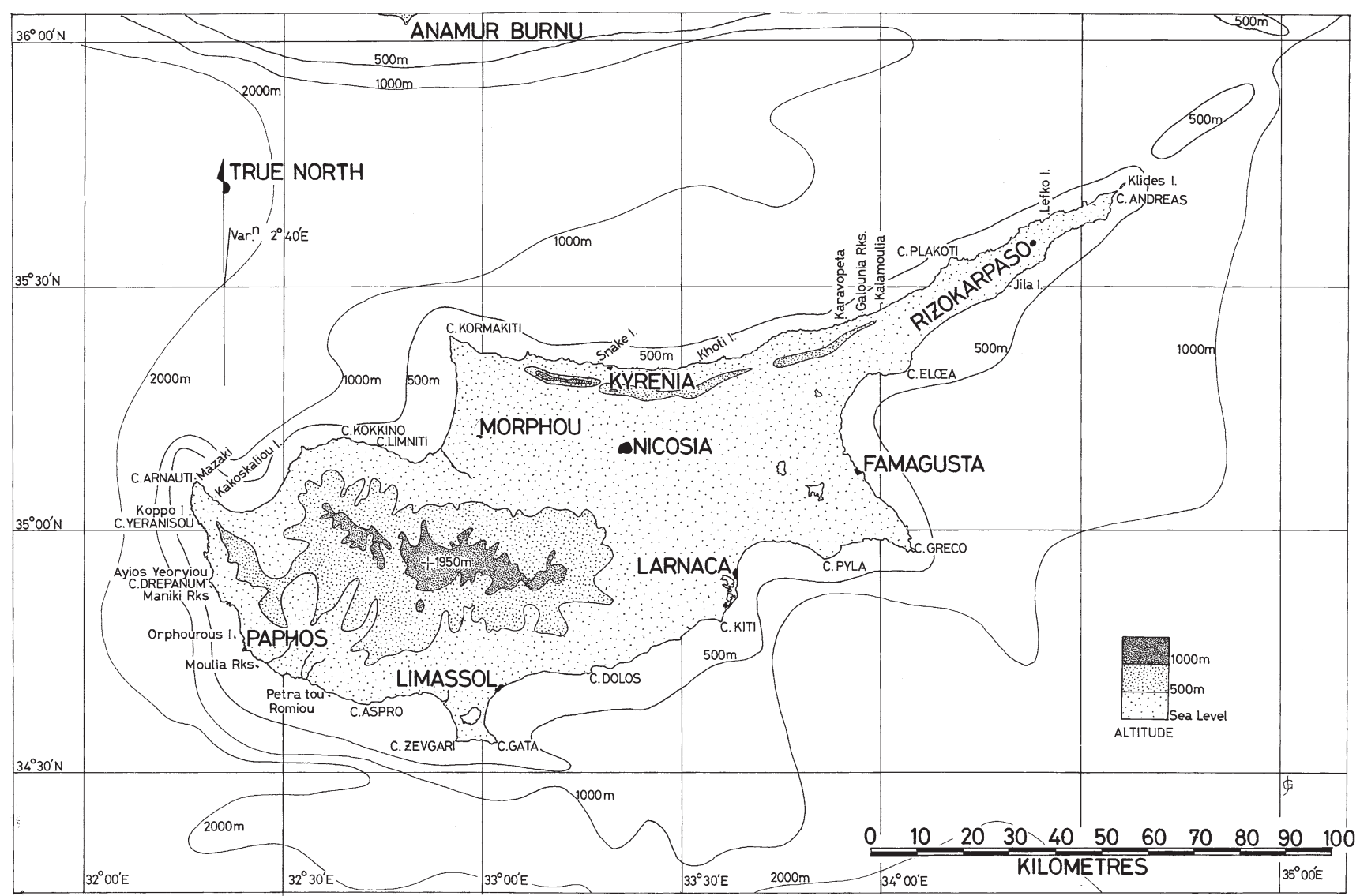

Fig. 3.1 Map of Cyprus showing Cape Andreas and the Khlides Islands

tours around the Cape and an estimate of the swim-line survey work that needed to be undertaken (see Fig. 3.3).

Once the vessel survey was completed, the swim-line surveys were undertaken, once again using horizontal sextant angles to plot the positions of the swim-lines. Different swim-line techniques were used in 1969 and 1970 and the results are shown in Fig. 3.4. Once a site was located, it was photographed and surveyed. At the large wreck sites, photographs were taken in order to create a photomosaic. To do this thin platted ski rope (selected because of its low stretch) marked at metre intervals, was laid out along the long axis of the site. This was used as a scale and to help the photographer ensure that the site was adequately covered. It was, by coincidence, this technique proved to be the most successful in processing the legacy data. The film was developed onsite. Images were printed and then manually laid up to create a photomosaic.

From the results of the 2 years surveys a large quantity of information was obtained from the swim-line work; this material was divided into three categories:

1. Wreck sites with ceramics, including material that may possibly be jettison;
2. Anchor sites-areas where anchors were closely associated; and

3. Individual anchors.

\subsubsection{Wreck Sites with Ceramics}

A total of ten pottery sites were located; some sites are little more than objects from spillage or jettison (Sites 1, 14 and 18). Sites 12 and 16; Sites 10 and 14; and Sites 17 and 24 had material that appears to be interrelated and it is difficult to decide whether the sites represent separate or associated events.

Site 12 , on the north side of the island No. 4 , is clearly a wreck site. It consists of an area approximately $20 \times 15 \mathrm{~m}$ containing numerous heavily concreted Corinthian-style roof-tiles and cover-tiles. Figure 3.5 shows a hand-laid up photomosaic of the site and Fig. 3.6 shows a drawing of the distribution of the sherds.

Site 16, a few metres to the south of islands Nos 4 and 5, consisted of a scattered collection of concreted sherds of amphorae and tiles, together with a small concentration of small bowls and plates, many of which were intact. The tile sherds to the west of Tag 3 may represent material that has 


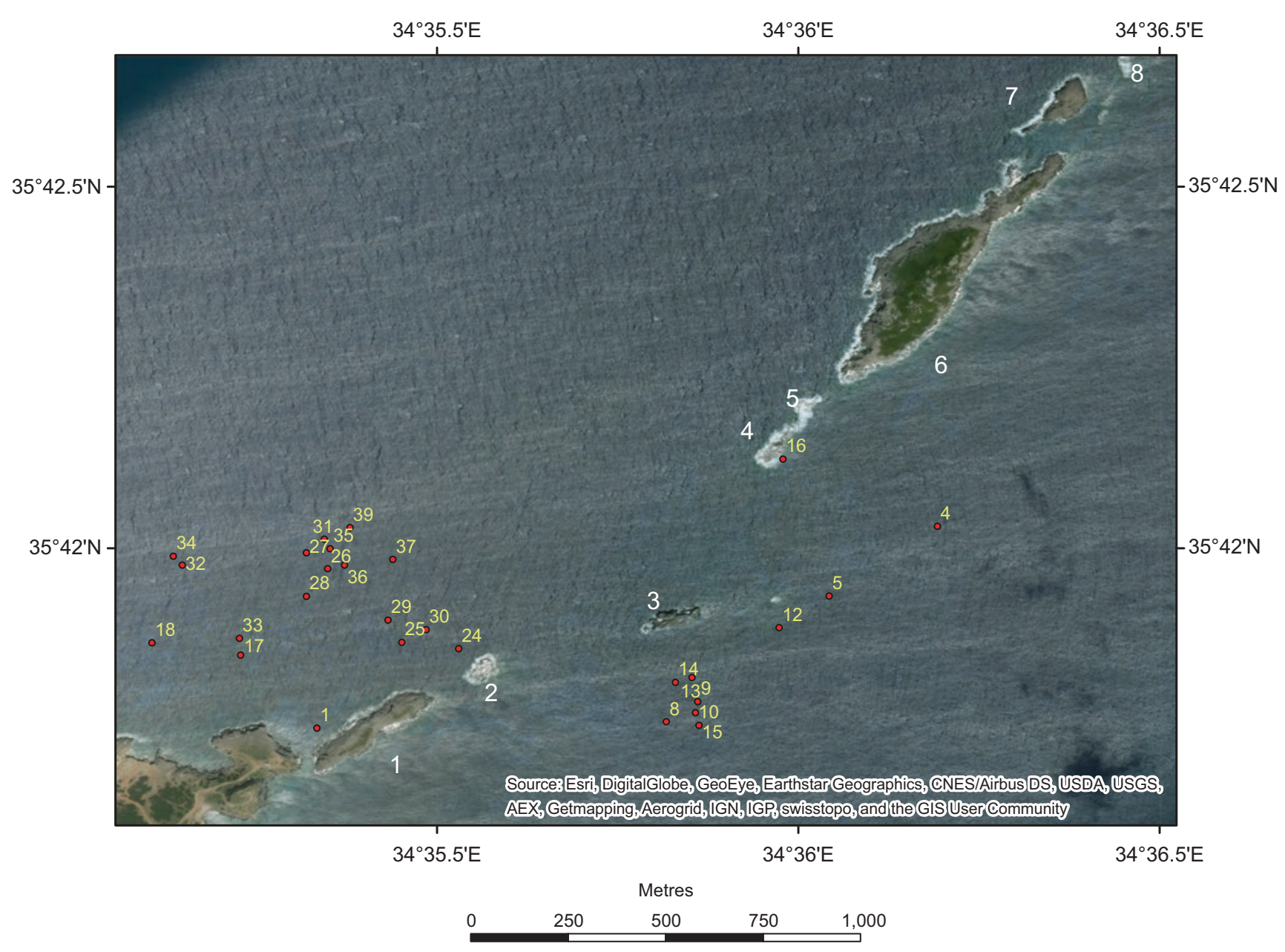

Fig. 3.2 Plan of Cape Andreas showing sites and latitude and longitude grid created from GIS

been washed over from the tile wreck, Site 12. It is difficult to establish if the two sites are associated and why such a large number $(c .25)$ of fine ware pottery objects should be concentrated, relatively undamaged, in such a small area.

Site 28 was located a week before the end of 1970 expedition. The superficial material lying at a depth of $20 \mathrm{~m}$ are Corinthian-style roof-tiles and cover-tiles (Fig. 3.7). The regular stacking indicated that the site was intact and represents the surface layer of cargo of a ship buried in a soft sand seabed. Two areas of tiles were noted. The larger area consisted of about 60 roof-tiles arranged in 4 rows, together with 8 cover-tiles; a further layer can be identified underneath these. The smaller area consists of about 15 tiles (Green 1971a).

Sites 17 and 24 lie around the north side of the second island; Site 24 was located by CAUSE in 1967 and was further investigated in 1969 (see Green 1969, Figs. 11 and 13).

Site 10 was located in 1969; it lies to the north of the rocks between the third and fourth islands. It is one of the most difficult sites to analyse, as the material is spread out over a large rocky area, $50 \times 20 \mathrm{~m}$. A variety of amphora sherds of different types and periods have been noted and recorded (Green 1969, Figs. 7 and 8). The team members constructed a large-scale mosaic of the site in order to try to produce a detailed plan. The initial impression is that this site represents spillage or jettison from several periods, rather than from several wrecks.

Site 1 consists of several looped handles and flat amphora bases concreted to the rocks around the southwest corner of the first island. In view of the small number of amphorae, this site can only represent jettison or spillage.

Site 18 consists of looped handles and pointed feet of amphorae scattered over an area of $300 \mathrm{sq}$. $\mathrm{m}$. It is situated to the north of the small group of rocks off the south side of the Cape. In view of the considerable amount of pottery (and beer bottles) in the area it is likely that this has been used as a lee shore by ships since antiquity. The site therefore probably represents jettison of damaged amphorae from a ship sheltering and waiting for favourable winds.

Site 14 lies on the south side of the rocks mentioned with reference to Site 10 . The site consists of a few tiles and amphorae, possibly jettison or spillage. It is surprising that out of the ten sites described, five consist mainly of looped-handle 


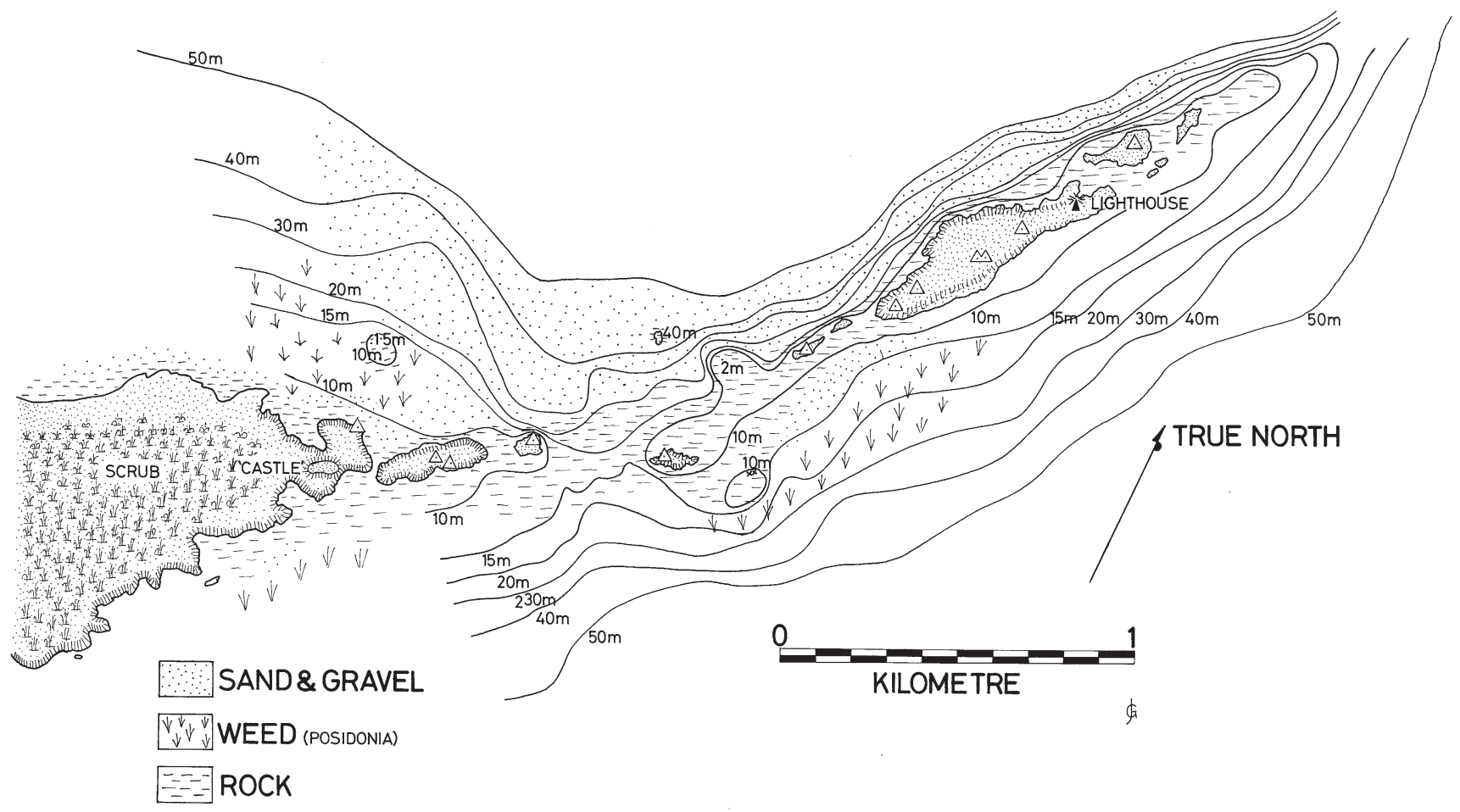

Fig. 3.3 Hydrograph chart of Cape Andreas produced from survey conducted in 1969

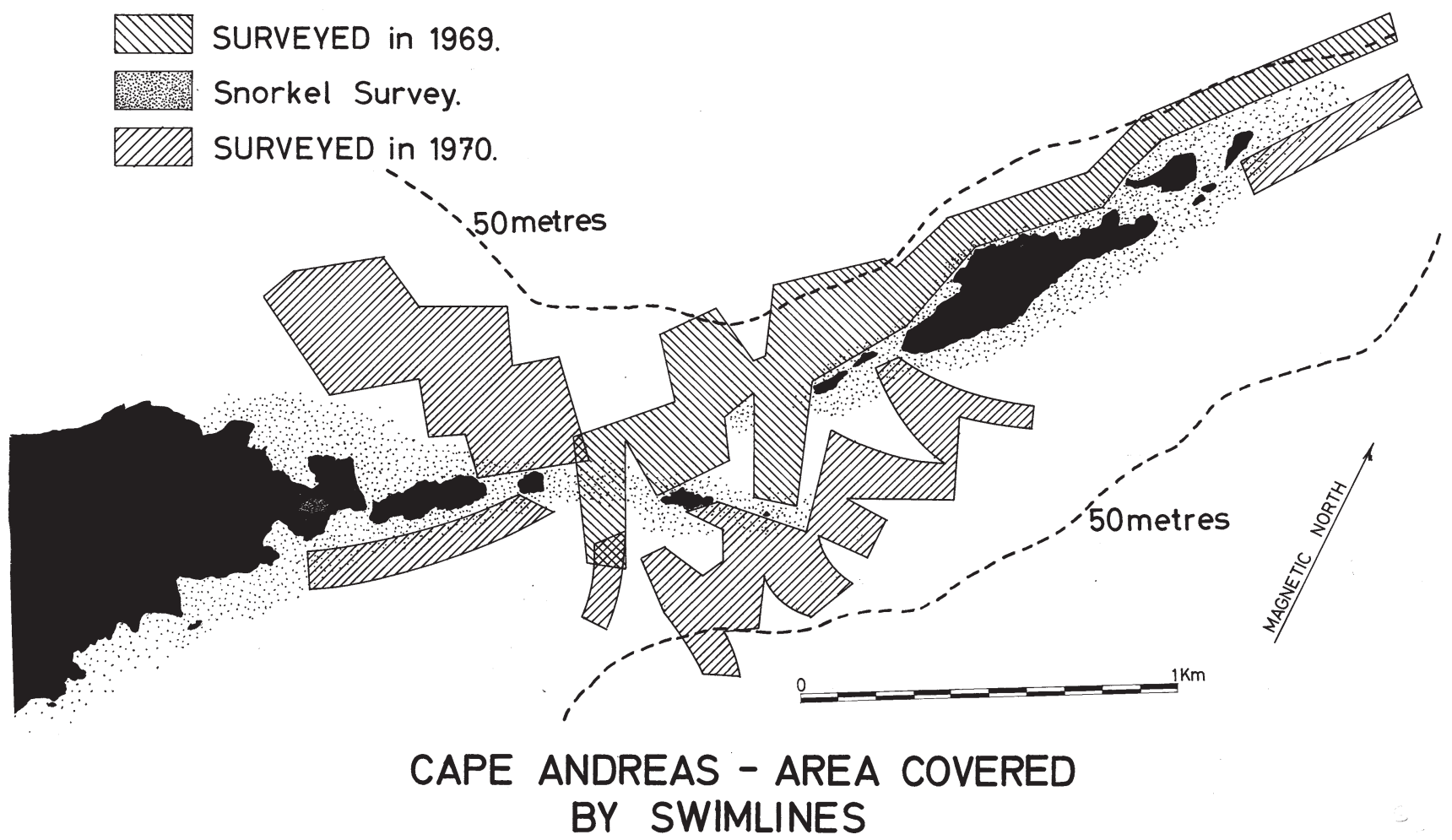

Fig. 3.4 Swim-line surveys of 1969 and 1970 


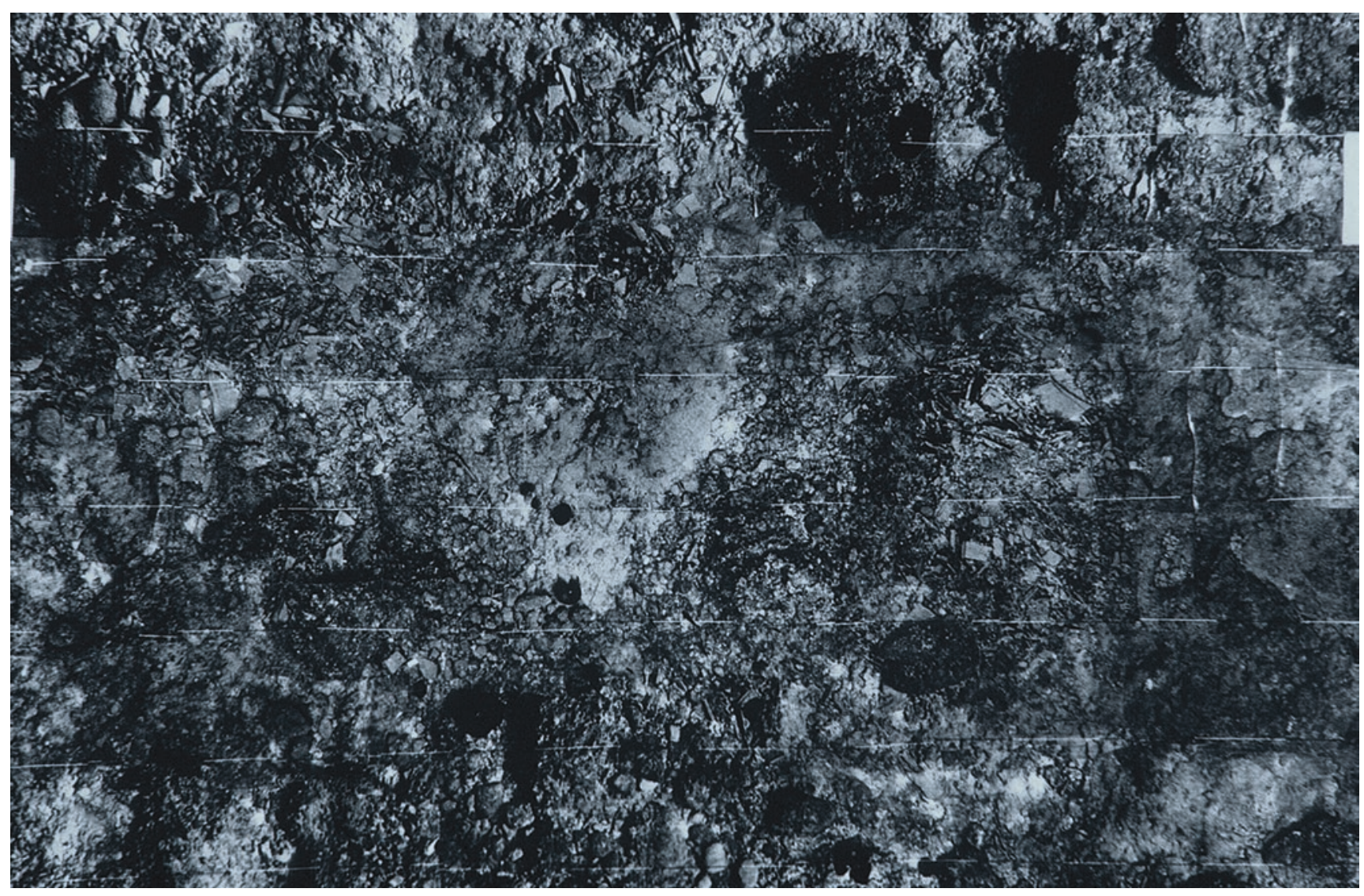

Fig. 3.5 Photomosaic of Site 12 produced in 1970

amphorae and four are tile sites. Sites 12 and 28 are clearly complete wrecks of ships carrying tiles as a cargo.

\subsubsection{Anchor Sites and Individual Anchors}

Four anchor sites were recorded on the north side of the Cape Andreas. Two of the sites (23 and 26) were areas containing a large number of different types of anchors. Sites 23 and 26 were located at the point where the gently upward-sloping sand seabed changes to a steep rock cliff face. Site 23 has a total of 28 anchors: 18 iron, 8 lead and 2 stone. The positions of a total of about 50 anchors were recorded, but only about half were recorded photogrammetrically.

\subsubsection{Reworking the Legacy Survey Data}

As mentioned, in the late 1960s, surveying was limited to optical systems. As was typical in those days, relative position was accurate, but absolute position, in normal circumstances, was almost impossible to obtain. When accurate GPS first became available, most hydrographic charts needed to be corrected to conform to the absolute information. The plans produced in the 1960s, although accurate, therefore, could not be given precise latitude and longitude or be applied with any certainty to accurate modern maps or charts and could only be applied to large-scale Admiralty charts.

Using ArcGIS it was possible to georeference the plans produced in the 1960s that had used the outline features on the early aerial photograph. Using the World Map in Arc GIS, it was then relatively simple to identify coastline features on the aerial photograph and the World Map and thus complete the georeferencing. As the survey stations had been transferred to the plans these could then be located on the GIS. With this information it was possible to place all the survey data from the 1960s on the GIS and attribute them relatively accurate latitude and longitude coordinates. Thus, all the sites now have geographic coordinates with an estimated position accuracy of about $\pm 5 \mathrm{~m}$ (see Fig. 3.2).

\subsubsection{Reworking the Legacy Photographic Data}

A total of 69 black and white $35 \mathrm{~mm}$ films were taken during the expeditions representing about 1700 images. The images were assessed for suitability for processing using Agisoft 
Fig. 3.6 Drawing taken from the photomosaic showing the ceramic material
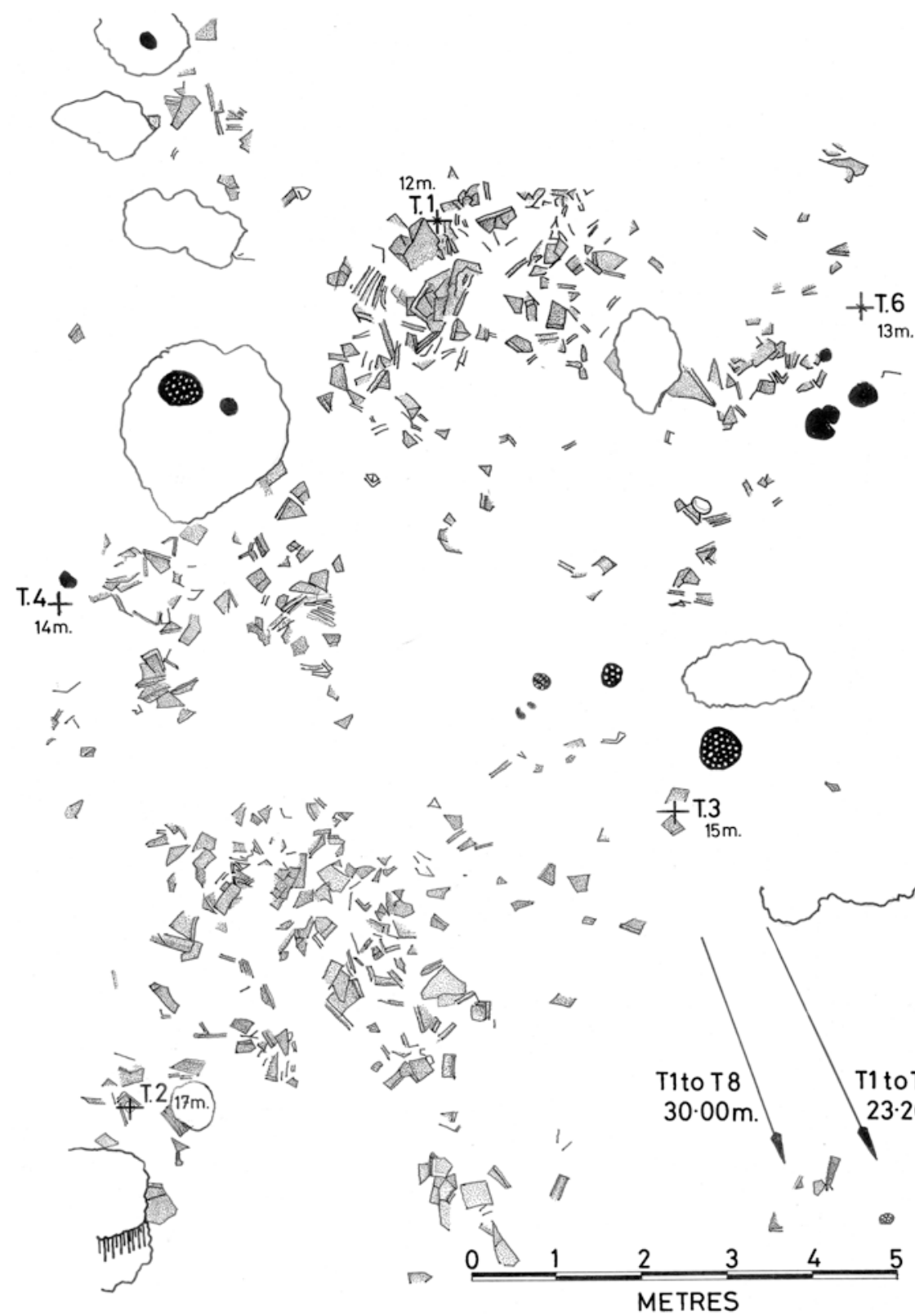

$\stackrel{D}{2}$

WRECKSITE 12

DRAWN FROM PHOTOMOSAIC
PhotoScan/Metashape software. Initially, photos that were obviously unsuitable were rejected. This left photos that were mosaics of large sites and groups of photos of single or multiple objects such as anchors or ceramics.

\subsubsection{Agisoft PhotoScan/Metashape}

The images from Site 12 were selected first. Any image with a grid frame was rejected, as the grid frames were moved around the site and, thus, made the alignment for Agisoft
PhotoScan/Metashape difficult (the option of masking the frames in Agisoft PhotoScan/Metashape was decided to be unnecessarily burdensome due to the large number of photographs). There were 99 images in the data set that had originally been used to construct the photomosaic. These were run through a high-end workstation with 4 X7560 Intel $^{\circledR}$ Xeon $2.26 \mathrm{GHz}$ CPUs and $512 \mathrm{~GB}$ of RAM. The Agisoft PhotoScan/Metashape settings were at the highest possible resolution. The alignment took $20 \mathrm{~min}$ resulting initially with 25 cameras out of the 99 aligning, giving 54,347 tie points and a 3D model with around 9.5 million faces 
Fig. 3.7 Site 28
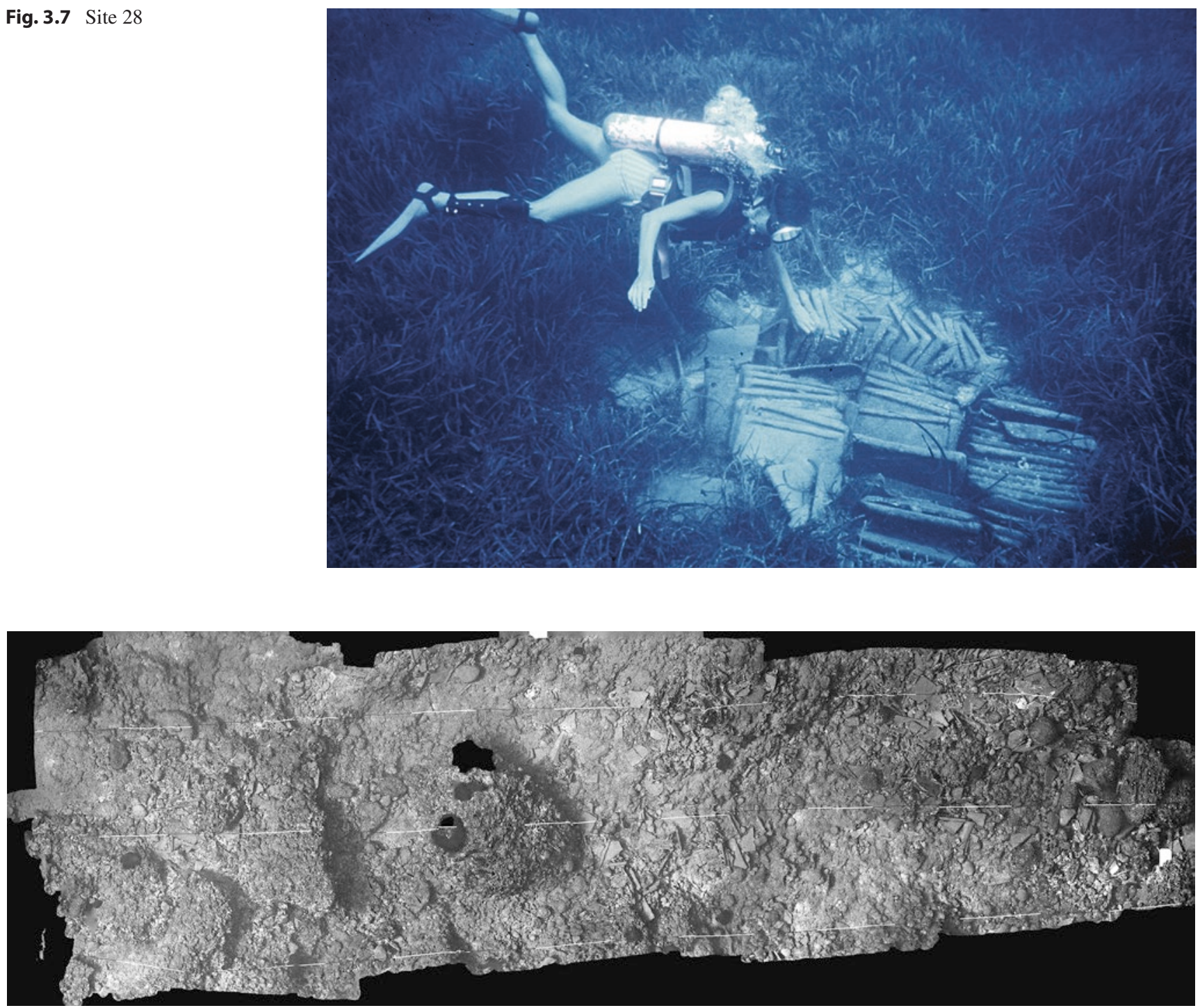

Fig. 3.8 PhotoScan/Metashape ortho-photograph of Site 12

(Fig. 3.8). The 25-camera chunk was then isolated and the program was re-run with the remaining 74 images. The second process aligned a further 23 cameras with 40,246 points, taking $1 \mathrm{~h}$ to build dense cloud and an hour to create the mesh (Fig. 3.8).

A similar method was used on Site 10 producing a good quality 3D image of the site (Fig. 3.9). Attempts to produce 3D images of the anchors, however, were generally unsuccessful partially because there were not enough photographs from different angles and in general the photographs had a 3D grid frame included in the view that disrupted the processing.

The well-known problem with Agisoft PhotoScan/ Metashape is that the program is a 'black box' and running the program on the same set of data produces different results on different occasions. In addition, there are many settings that can produce slightly different results. For the Cape
Andreas material, a number of different models were produced. In general, the photomosaic runs without grid frames were the most successful in converting to $3 \mathrm{D}$ visualizations, however, the masking feature in Agisoft PhotoScan is yet to be tested on this material.

\subsection{The Santo António de Tanná Shipwreck}

In 1978 and 1979, photographic recording of the Portuguese wreck of the Santo António de Tanná (1697) was undertaken (Piercy 1976, 1977, 1978a, b, 1979a, b, 1981 \& Sassoon 1982). The project, under the auspices of the National Museums of Kenya and the Institute for Nautical Archaeology, involved the excavation of the ship that lay about $50 \mathrm{~m}$ from shore under the walls of Fort Jesus, Mombasa, Kenya. The frigate Santo António de Tanná had been dispatched by the 


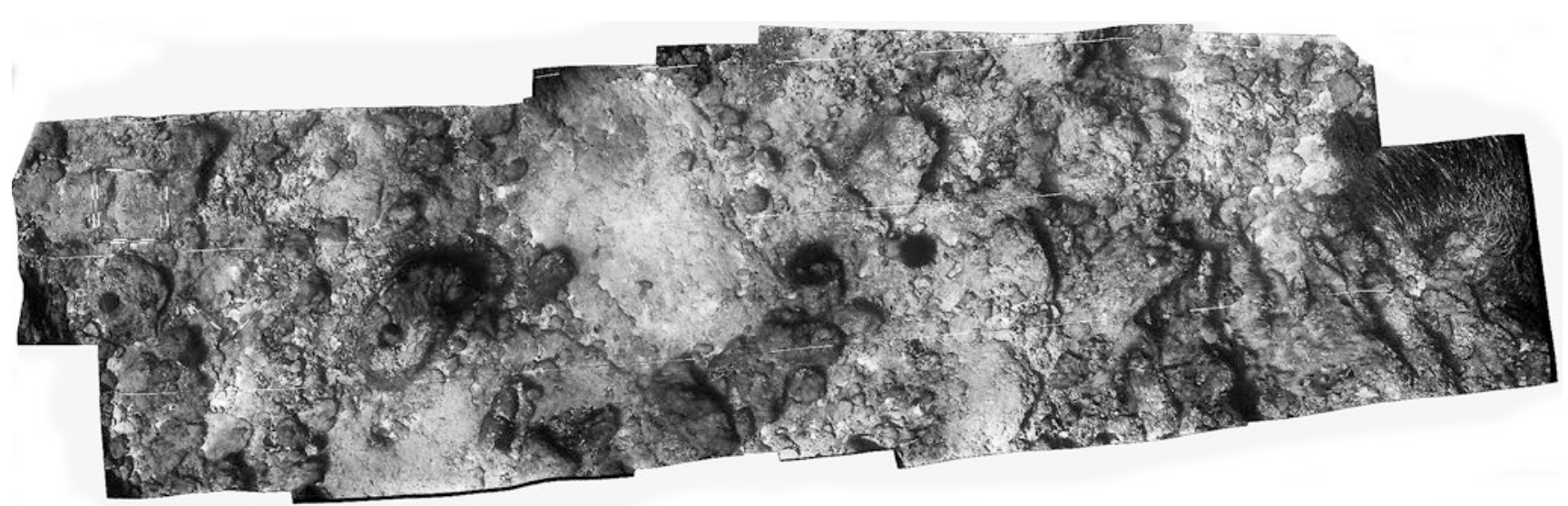

Fig. 3.9 Site 10 mosaic PhotoScan/Metashape

Portuguese Viceroy in Goa to relive the fort that was under siege by the Omanis. On arrival in 1697 the General anchored the frigate in front of the fort and was informed that all the Portuguese in the fort were dead and that about 25 Swahili men and 60 women were left defending the fort. The fort was immediately relieved, however, some time later the vessel broke its moorings, drifted onto the shore and sank (Fraga 2007; Killman 1974; Killman and Bentley-Buckle 1972). The fort finally fell to the Omanis in 1698 after a 3.5 year siege.

During the excavation of the site in 1978 and 1979 photographic recording was undertaken during periods of good visibility (Green 1978). This situation corresponded with the High Water Spring Tides, which brought clear oceanic water into the river that normally had low visibility (c. 2-3 m compared with $10-15$ m during the High Water Springs).

The surveying techniques used to record the structure of the ship uncovered during the second season were based on the experience of the first season and were devised to meet the rather peculiar conditions of the site. Since it was required to produce detailed 3D plans, both photogrammetry and standard measurement recordings were used. The nature of the site, however, produced limitations in the application of both techniques. Poor visibility, except at high spring tides, precluded the constant use of photographic recording. Likewise, poor visibility and tidal currents made tape measurements unreliable and it was difficult to establish an accurate baseline for recording purposes. Additional problems were encountered because of the peculiar orientation of the ship, which lay on a steep slope with its bow inclined $20^{\circ}$ down the slope and with a lateral tilt of $54^{\circ}$ to port. The keelson was twisted along its exposed length, and there was evidence at the scarf joint that the stern section, including the keelson, had moved in relationship to the bow. These distortions have been extremely difficult to sort out because of the unusual orientation and the lack of a useful datum, such as the base of the keel to work from.

The overall shape of the structure was recorded by measuring profiles at $1 \mathrm{~m}$ intervals across the hull of the ship at right angles to the keelson. A stereo-photogrammetric survey over the whole of the inside of the ship was made so that detailed information of the internal structure could be recorded. Control points were put in place and surveyed so that the photogrammetric survey could be related to the profiles and incorporated in the overall plans. Detailed measurements were also made of the keelson, which served as the base line for the survey. Fraga (2007) produced a plan of the site based on the tape measurements taken in 1978-1979 and related this to the contemporary seventeenth and eighteenthcentury Portuguese naval architecture texts of Lavanha (1610) and Oliveira (1578-1581).

\subsubsection{Profile Recording}

The profiles were measured at $1 \mathrm{~m}$ intervals along the keelson using a circular $0.75 \mathrm{~m}$ diameter, $360^{\circ}$ protractor, graduated in half degrees and mounted on a bar measuring $1 \mathrm{~m}$ in length (Fig. 3.10). The bar was clamped to the upper (starboard) side of the keelson so that the plane of the protractor was at right angles to the keelson. A pin mounted at the centre of the protractor acted as a swivel for a $0.5 \mathrm{~m}$ length of thin string with a stirrup at the end, through which a $10 \mathrm{~m}$ survey tape was threaded. The angle and the true distance were recorded against the record number. Using this technique, it was possible to work in poor visibility $(c .1 \mathrm{~m})$ even when the two operators were out of sight of each other. The overall method was fast and reasonably accurate. In a $61 \mathrm{~min}$ dive, with experience, it was possible to do two $6 \mathrm{~m}$ profiles consisting of a total of 80 readings. Using a small hand calculator (Hewlett Packard 25), the polar co-ordinates were 


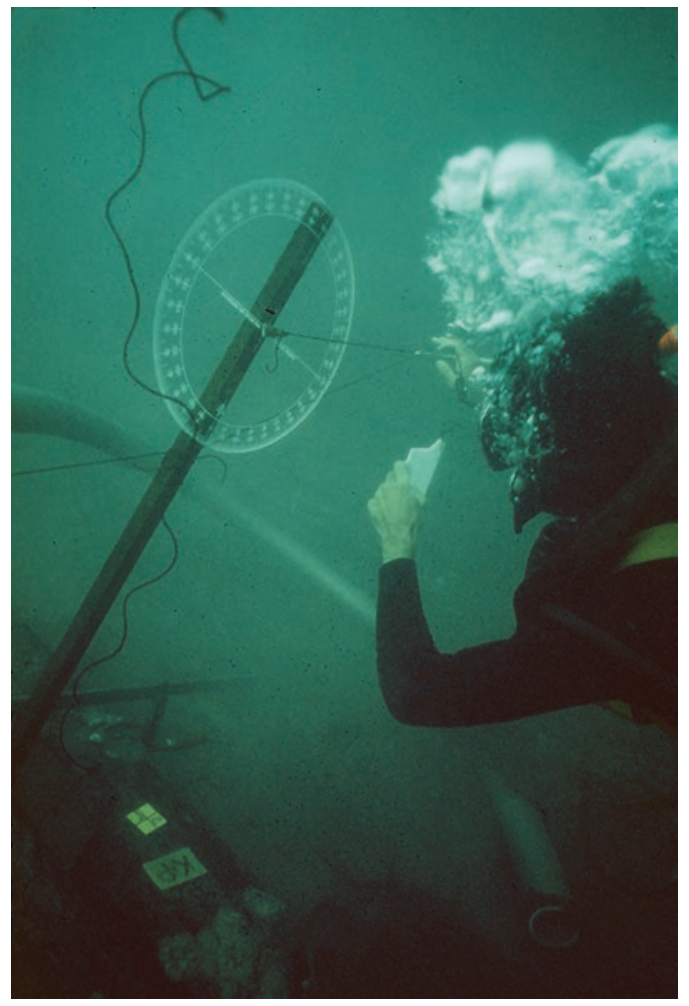

Fig. 3.10 Circular protractor used to record profiles

converted to rectangular (or $\mathrm{x}$ and $\mathrm{y}$ ) co-ordinates, which greatly facilitated the plotting of data. The results, when converted to rectangular co-ordinates, were plotted on graph paper. The accuracy of the technique was basically governed by the size of the protractor and was about $\pm 2 \%$.

\subsubsection{Trilateration Survey}

The survey of the control points was carried out by trilateration. The upper starboard edge of the keelson was selected as the baseline. The control consisted of tags driven into the keelson and port and starboard extremities of the site at $2 \mathrm{~m}$ intervals. A $2 \mathrm{~m}$ rod was clamped against, and at right angles to the upper edge of the keelson opposite each of the keelson controls. Measurements were made to the three nearest controls on both the port and starboard sides of the site, from the base of the rod and at the keelson, and the mark $2 \mathrm{~m}$ above the keelson. Thus, for example, if the rod was at the $4 \mathrm{~m}$ keelson mark, 16 measurements were made from the base and top of the rod, 6 to the port 2, 4 and 6 marks, 6 to the starboard 2, 4 and 6 marks and 2 to the keelson 2 mark and 2 to the keelson 6 mark. The offsets of the control marks on the keelson to the rod were measured, and the angle of the rod to the true vertical was measured using a carpenter's level. With this informa- tion, it was, at the time, still not possible to calculate the 3D coordinates of all the control points. This was to come later, but at the time we were aware that there were ways to do this and rather futile attempts were made using the programmable calculator.

\subsubsection{Photographic Recording}

Two Nikonos III cameras were mounted $0.5 \mathrm{~m}$ apart on an aluminium stereo bar. The cameras were adjustable and provided with screws so that the vertical and horizontal tilt of the camera could be adjusted. Two targets, with viewing holes through their centres were mounted $0.5 \mathrm{~m}$ apart on a levelled bar at about $5 \mathrm{~m}$ from the levelled stereo bar. Using plane mirrors in place of the lenses, the stereo bar was adjusted so that the image of the target in the mirror, when viewed through the corresponding target, coincided with the centre of the optical axis of the fixed camera. This enabled the cameras to be adjusted so that the optical axes were accurately parallel and perpendicular to the stereo bar. The stereo bar was then mounted on the photo tower to be used underwater and the cameras remained on the bar for the whole of the survey. At the end of each underwater session, the bar was removed and taken ashore, but the cameras remained on the bar and the film could be extracted from the camera without disturbing the camera positions.

The photo tower consisted of a $2 \mathrm{~m}^{2}$ base graduated in $0.1 \mathrm{~m}$ intervals, with stays supporting a $2 \mathrm{~m}$ bar, $1.88 \mathrm{~m}$ vertically above the base (Fig. 3.11). The bar was constructed so that, when the stereo bar was fitted to it, the optical axes of the camera lenses lay on the centre line of the base square, equidistant about the centre of the grid. Fine adjustments were made using the mirror system to set the photographic plane of the stereo bar parallel to the plane of the grid frame. With this arrangement, there was a photographic overlay over the whole of the $2 \mathrm{~m}$ grid frame, the $15 \mathrm{~mm}$ lens had, in fact a focal length in water of $20.8 \mathrm{~mm}$.

Table tennis balls on $0.5 \mathrm{~m}$ of white string were attached to the mid-points of each side of the grid frame. As these floated upright in water, it was possible to determine the orientation of the camera plane to the true vertical. The orientation of each pair of stereo photographs could be determined for reference purposes by extending the line of the strings to the nadir point. The line joining the nadir point to the principal point of the photograph, gave the direction of the true vertical, and the ratio of the length of this line to the effective focal length of the photograph gave the tangent of the angle of the true vertical to the camera axis. In practice, however, the small current that was always present prevented this from being effective. 
Fig. 3.11 Phototower on site

showing slope of site

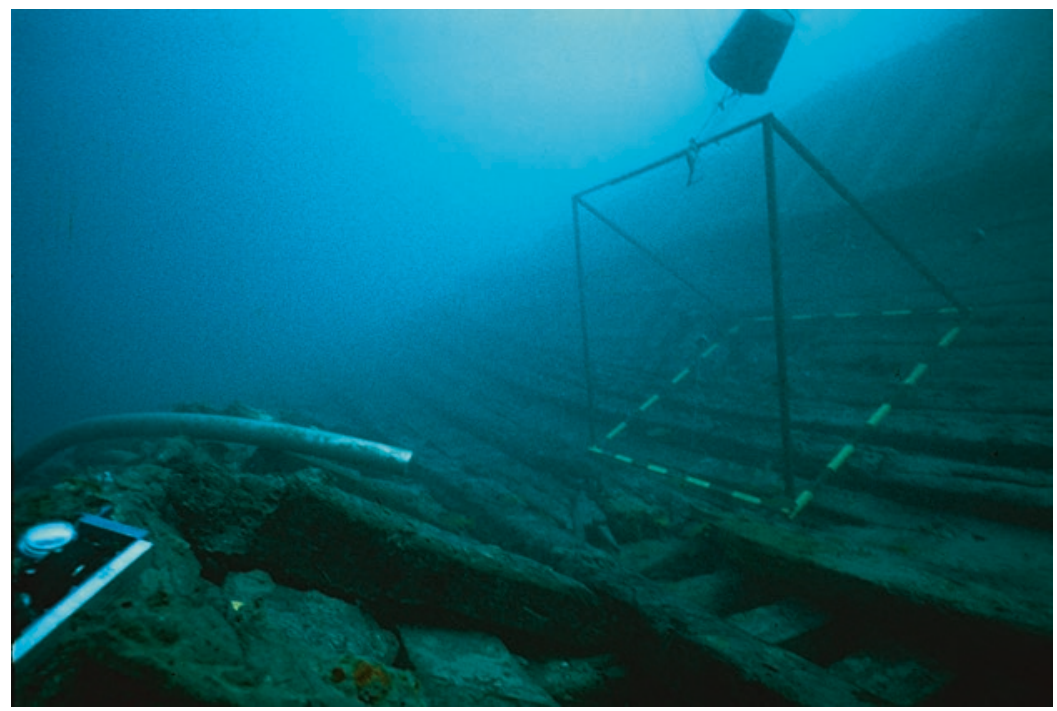

Photographic exposures were made by moving the tower at $1 \mathrm{~m}$ intervals, thus ensuring good end-lap between the stereo pairs although it was difficult to ensure that the adjacent runs had good overlap. Using two plastic buckets for buoyancy the photo tower could be moved around quite easily by one person, although for accurate positioning two people were required. Great care had to be taken not to stir up sediment, particularly as most photography was carried out at high water when there was little current. Considerable variation in the quality of photographs was noted over the three High-Water Spring Tide periods when this photogrammetric coverage was carried out. This was due partially to the variation in the quantity of suspended matter in the water and also to the light level caused by the effects of clouds and the time of day. In many cases the coverage was a compromise, particularly as the best visibility conditions, corresponding to the highest tides, fell just after dawn or just before sunset, when the light levels were too low for good results. Under normal circumstances, using FP4 rated at 400 ASA and given twice normal development in D76, exposures ranged from f2. 8 at $1 / 30$ to f5.6 at $1 / 60$.

Considerable planning was required in preparation for the High-Water Spring Tide periods when this type of photogrammetry was possible. The timbers had to be cleaned of any silt, sand and other material that collected as a natural result of the muddy water and stray discharge from the airlifts. If possible, airlifting was terminated about an hour before high-water, and the timbers were then brushed to remove the fine silt. No other diving was carried out during the photographic runs to prevent disturbance of the fine silt in other areas on the site. The photomosaic was created by printing the images and then gluing them down on a paste board (Fig. 3.12).

\subsubsection{Agisoft PhotoScan/Metashape}

The most significant problem with processing the Santo António de Tanná material in Agisoft PhotoScan/Metashape has been the presence of the photo tower and table tennis balls. Because the tower was placed on the interior surface of the hull, the orientation of the tower, in relation to the Cartesian coordinates of the hull of the ship, was different in each photo-pair. Agisoft PhotoScan/Metashape, thus, has the problem that in each photo there is a tower frame in exactly the same position and a view of the hull in a random orientation. Work on the material has proceeded over the years since the introduction of Agisoft PhotoScan/Metashape in 2010 and results have slowly improved. A major breakthrough occurred thanks to a series of photographs taken using the stereo bar by itself without the tower. On one particularly clear day, the bar was swum at a high altitude over the site and a series of stereo photographic pairs were recorded. These were run through Agisoft PhotoScan/Metashape and a good 3D model was obtained (Fig. 3.13), however because of the height, the resolution is not particularly good.

Currently a project at Curtin University's HIVE has just been completed where the photographs and survey information were combined to develop a high-resolution orthophotograph (Fig. 3.14) and a DEM (Fig. 3.15). Using the masking technique in Agisoft PhotoScan/Metashape, the tower and the table tennis balls were removed, and a high-quality mesh has been achieved, although with some holes in the coverage (see Shaw 2018).

In addition, the stereo pairs were processed to create individual models that were stitched together to produce a different approach to obtaining a 3D model. Essentially the objective of the project is to discover a method of processing 


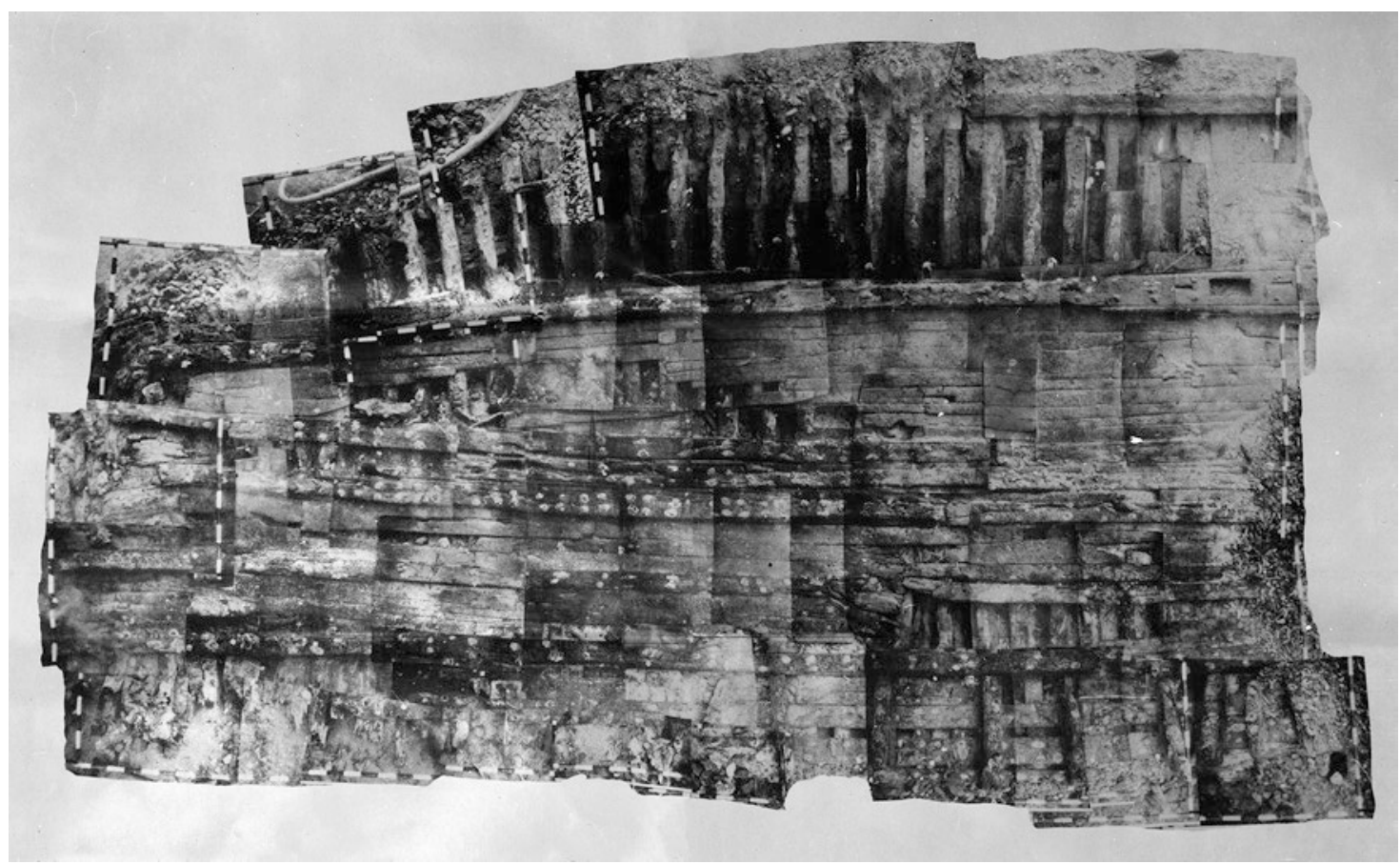

Fig. 3.12 Handmade photomosaic

Fig. 3.13 Perspective view of 3D model created in PhotoScan/Metashape

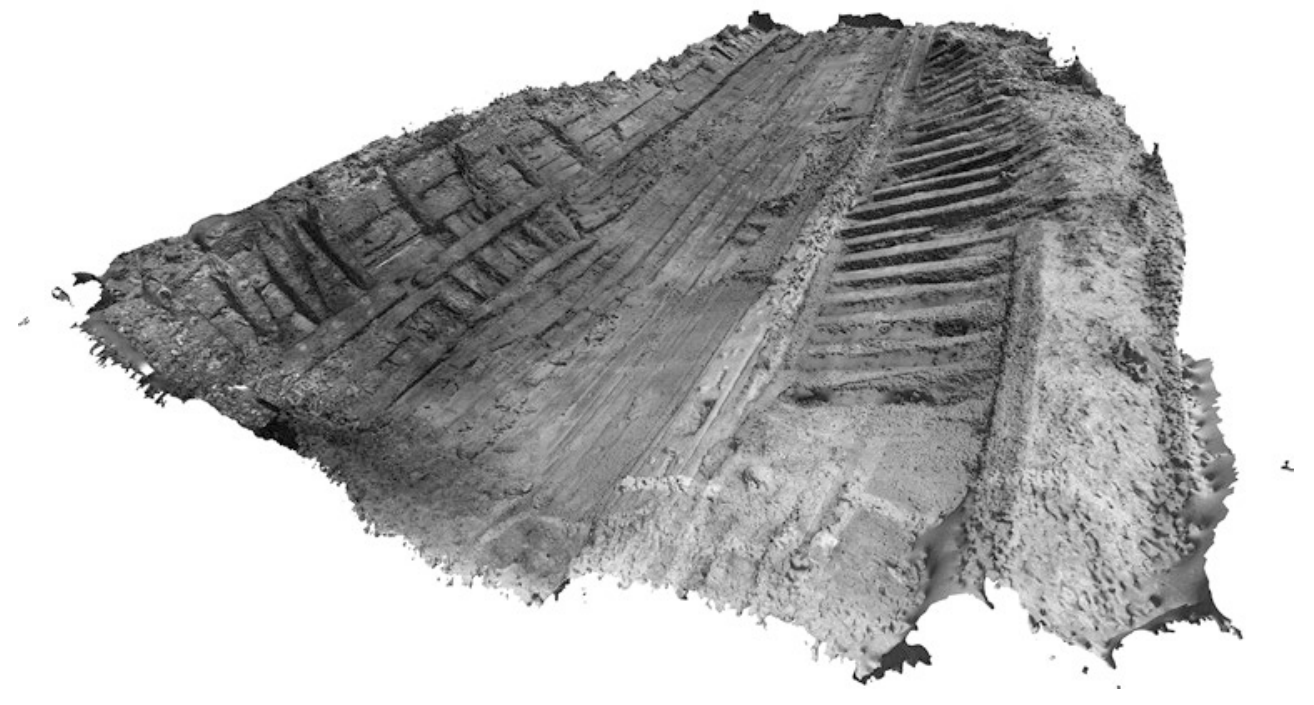

stereo photographic coverage to produce a 3D model. This will have enormous implications for legacy photography and a method of reassessing excavations.

\subsection{Conclusions}

The ultimate question is what does the $3 \mathrm{D}$ visualization of legacy data do for the archaeologist? It is obvious that visualization of a site in $3 \mathrm{D}$ is interesting and has a considerable significance in presenting the underwater archaeological world to the public. It remains less clear, however, what the implications are for the archaeological world. One significant issue is the ability to obtain an orthomosaic of a site, which compared with the hand-produced photomosaicmade by laying up paper prints of images and matching them-is a significant improvement in accuracy. Working with $2 \mathrm{D}$ prints of a site with any significant $3 \mathrm{D}$ component is always a compromise. The ability to produce an othomosaic and, thus, create a plan that is geometrically correct is 


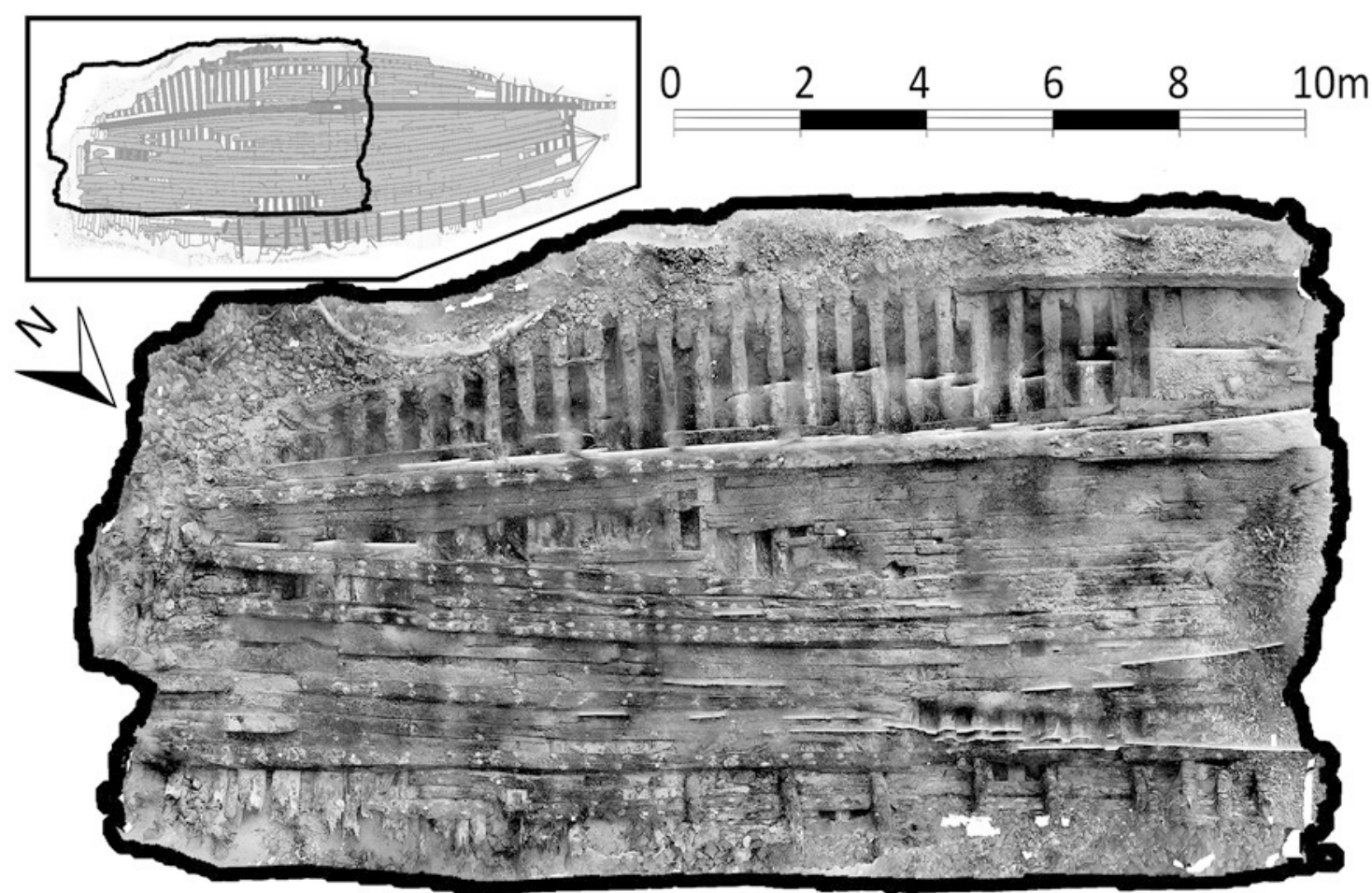

Fig. 3.14 High resolution orthophotograph created in PhotoScan/Metashape by HIVE

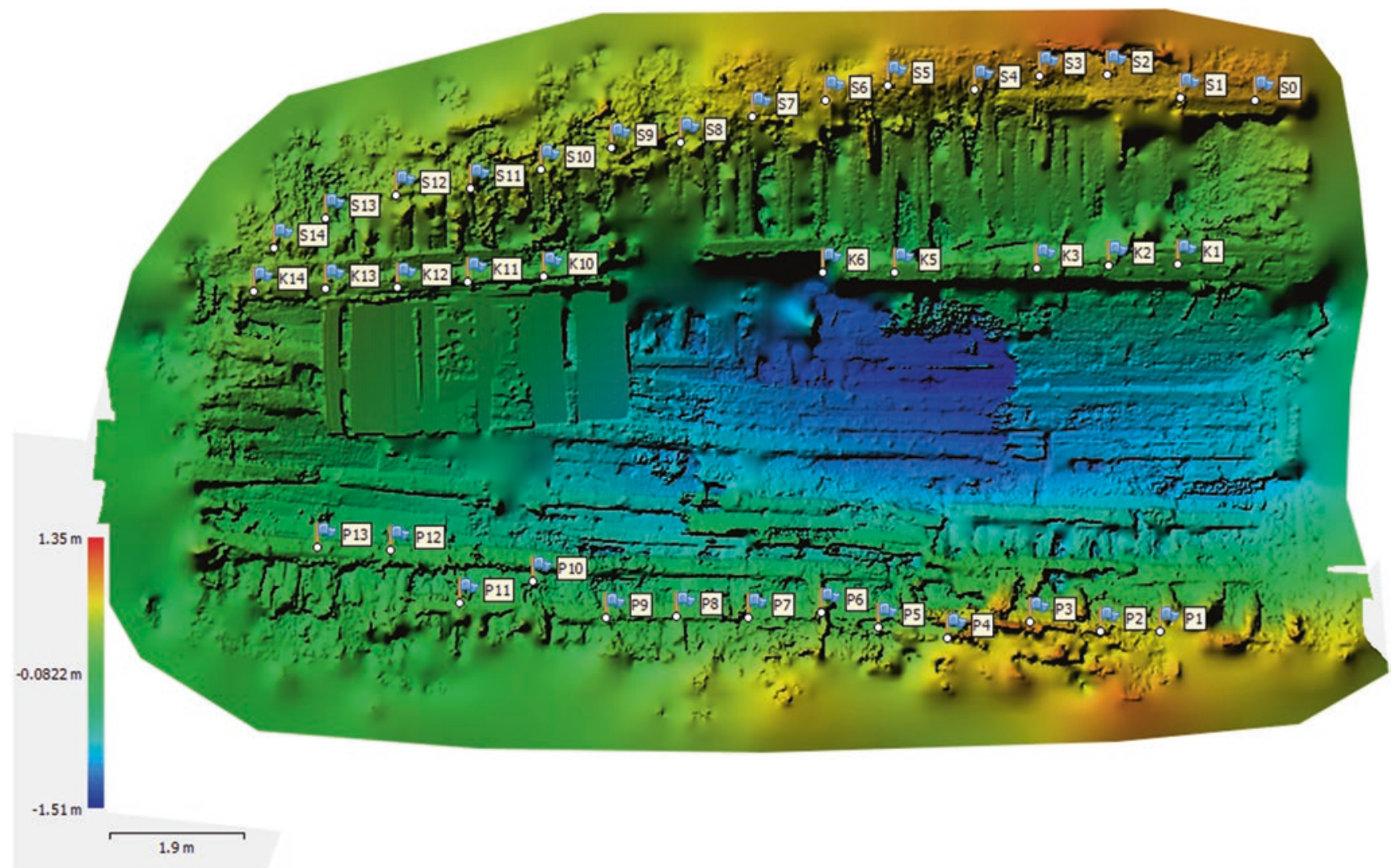

Fig. 3.15 A Digital Elevation Model (DEM) showing control points produced by HIVE 


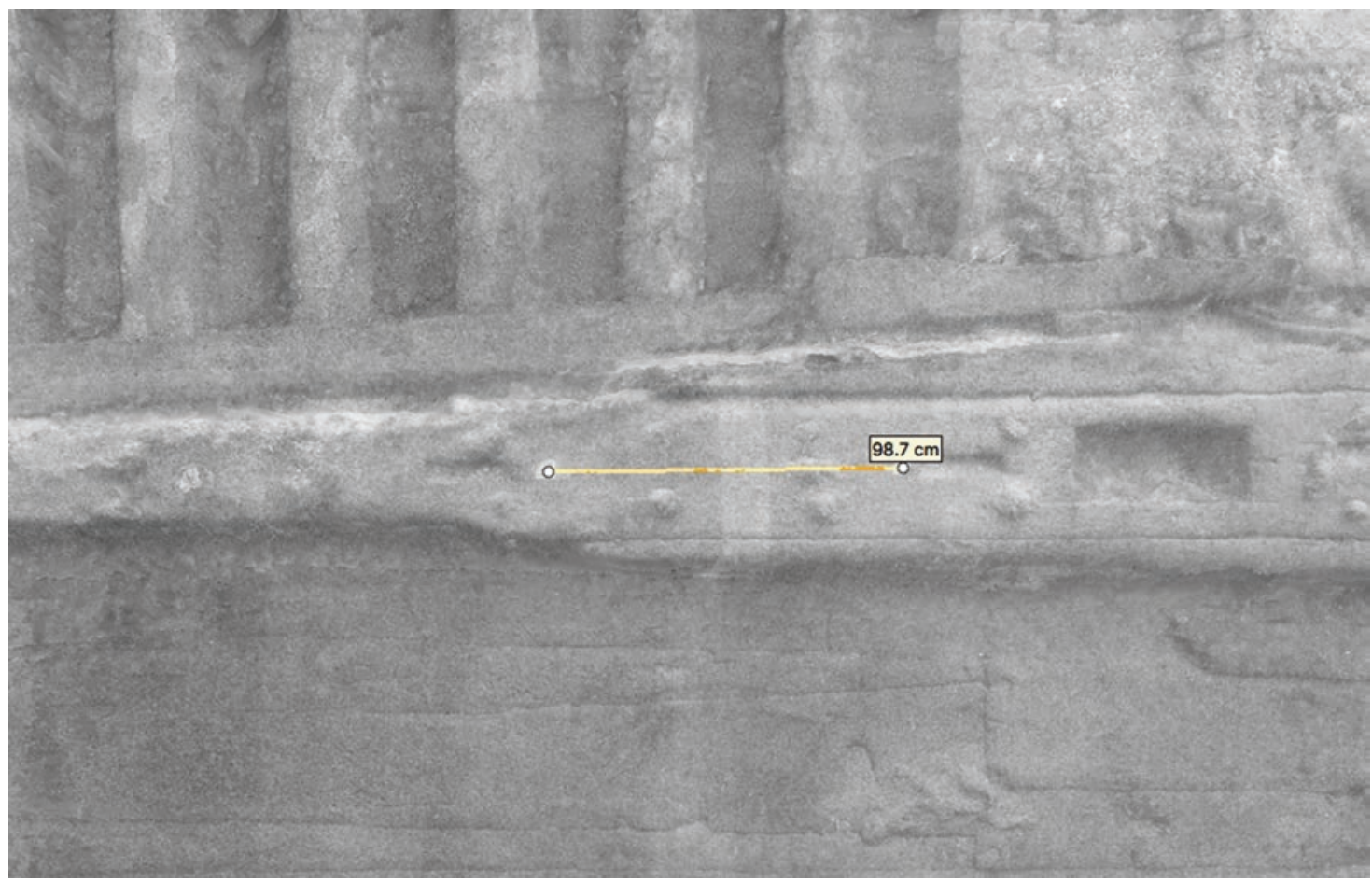

Fig. 3.16 Detail of PhotoScan/Metashape model of Santo António de Tanná keelson showing 3D measurement between two control points

significant in the interpretation of the site, particularly as most site photographs have scales included. The orthophotograph can easily be scaled as the survey lines are marked in metre intervals thus providing an overall site scale. It is thus possible to make a count, catalogue and measure the artefacts on the site, something that would be almost impossible with the paper-based photomosaic.

The question of 3D measurement of a site is more complicated. In the case of Cape Andreas, the sites were relatively flat so 3D measurements were less important. The situation with the Santo António de Tanná is much more interesting. The 3D model of the site is surprisingly detailed and enables almost any measurement from the site to be obtained. For example, the control points on the keelson, $1 \mathrm{~m}$ apart is shown in Fig. 3.16 as $98.7 \mathrm{~cm}$, this, considering that the photography was taken 40 years ago, is quite remarkable. This particular aspect of accuracy in a 3D model is currently under further investigation and will be the subject of a later report.

Acknowledgements The author would like to acknowledge the information supplied by Lachlan Shaw, the Curtin University intern, who worked on the Santo António de Tanná project as part of a grant from the Australian Research Council Linkage Grant Shipwrecks of the Roaring 40s (LP130100137). Also, Andrew Woods, Petra Helmholtz, David Belton and Joshua Hollick from Curtin University HIVE who supervised this project. I would like to thank Robin Piercy, the director of the Santo António de Tanná project for providing the photographic record of the site. Last, thanks goes to Patrick Baker and the Cape Andreas team for their help and support.

\section{References}

Bass GF, Throckmorton P, Taylor JP, Hennessy JB, Shulman AR, Buchholz H-G (1967) Cape Gelidonya: a Bronze Age shipwreck. Trans Am Philos Soc 57(8):1-177. https://doi.org/10.2307/1005978

Falkingham PL, Bates KT, Farrow JO (2014) Historical photogrammetry: bird's paluxy river dinosaur chase sequence digitally reconstructed as it was prior to excavation 70 years ago. PLoS One 9(4):e93247

Fraga TM (2007) Santo Antonio de Tanná: story and reconstruction. $\mathrm{PhD}$ dissertation, Texas A\&M University

Green JN (1969) The research laboratory for archaeology Cape Andreas expedition 1969. Research Laboratory for Archaeology, Oxford

Green JN (1971a) Cape Andreas: a survey of a tile wreck. Prospezioni Archaeologiche 6:141-178

Green JN (1971b) An underwater archaeological survey of Cape Andreas, Cyprus 1969-1970: a preliminary report. In: Blackman DJ (ed) Maritime Archaeology: proceedings of the 23 Symposium 1971 of the Colston Research Society held in the University of Bristol, 4-8 April. Butterworths, London

Green JN (1978) The survey procedure. Int J Naut Archaeol 7(4):311-314

Green JN, Hall ET, Katzev ML (1967) Survey of a Greek shipwreck off Kyrenia. Cyprus Archaeometry 10:47-56

Hydrographer of the Navy (1965) Admiralty manual of hydrographic surveying, vol 1. Hydrographer of the Navy, London

Killman J (1974) Fort Jesus a Portuguese fortress on the E. African coast. Clarendon Press, Oxford

Killman J, Bentley-Buckle AW (1972) A Portuguese wreck off Mombasa, Kenya. Int J Naut Archaeol 1(1):153-157. https://doi. org/10.1111/j.1095-9270.1972.tb00687.x

Lallensack JN, Sander PM, Knötschke N, Wings O (2015) Dinosaur tracks from the Langenberg Quarry (Late Jurassic, Germany) reconstructed with historical photogrammetry: evidence for large theropods soon after insular dwarfism. Palaeontol Electron 18(2):1-34 
Lavanha JB (1610) Livro Primeiro da Architectura Naval. Original edition, Lisboa, 1610

McAllister M 2018 'Seeing is Believing': investigating the influence of photogrammetric digital 3D modelling of underwater shipwreck sites on archaeological interpretation. PhD dissertation, University of Western Australia

Oliveira F (1578-1581) O Livro da Fábrica das Naus. Lisbon

Piercy RCM (1976) The Mombasa shipwreck. Inst Naut Archaeol Newsl 3(3):1-5

Piercy RCM (1977) Mombasa wreck excavation: preliminary report, 1977. Int J Naut Archaeol 6(4):331-347. https://doi. org/10.1111/j.1095-9270.1977.tb01033.x

Piercy RCM (1978a) Mombasa wreck excavation: second preliminary report, 1978. Int J Naut Archaeol 7(4):301-319. https://doi. org/10.1111/j.1095-9270.1978.tb01080.x

Piercy RCM (1978b) The 1978 season at Mombasa. Inst Naut Archaeol Newsl 5(4):1-5
Piercy RCM (1979a) Mombasa wreck excavation: third preliminary report, 1979. Int J Naut Archaeol 8(4):303-309. https://doi. org/10.1111/j.1095-9270.1979.tb01135.x

Piercy RCM (1979b) Mombasa. Inst Naut Archaeol Newsl 6(3):8

Piercy RCM (1981) Mombasa wreck excavation: fourth preliminary report, 1980. Int J Naut Archaeol 10(2):109-118. https://doi. org/10.1111/j.1095-9270.1981.tb00020.x

Sassoon H (1982) The sinking of the Santo Antonio de Tanna in Mombasa harbour. Paideuma 28:101-108

Shaw LR (2018) The photogrammetric analysis of the Santo Antonio de Tanna. http://museum.wa.gov.au/maritime-archaeology-db/maritime-reports/photogrammetric-analysis-santo-antonio-de-tanna. Accessed 6 Aug 2018

Wallace CAB (2017) Retrospective photogrammetry in Greek archaeology. Stud Digit Herit 1(2):607-626

Williams JCC (1969) Simple photogrammetry: plan-making from small-camera photographs taken in the air, on the ground or underwater. Academic, London

Open Access This chapter is licensed under the terms of the Creative Commons Attribution 4.0 International License (http://creativecommons. org/licenses/by/4.0/), which permits use, sharing, adaptation, distribution and reproduction in any medium or format, as long as you give appropriate credit to the original author(s) and the source, provide a link to the Creative Commons licence and indicate if changes were made.

The images or other third party material in this chapter are included in the chapter's Creative Commons licence, unless indicated otherwise in a credit line to the material. If material is not included in the chapter's Creative Commons licence and your intended use is not permitted by statutory regulation or exceeds the permitted use, you will need to obtain permission directly from the copyright holder. 